\title{
Belphégor
}

\section{Grivel, Charles. Le Corps défait. Études en noir de la littérature fin-de-siècle}

\section{Vittorio Frigerio}

\section{(2) OpenEdition \\ Journals}

Electronic version

URL: http://journals.openedition.org/belphegor/3382

DOI: $10.4000 /$ belphegor.3382

ISSN: 1499-7185

Publisher

LPCM

\section{Electronic reference}

Vittorio Frigerio, "Grivel, Charles. Le Corps défait. Études en noir de la littérature fin-de-siècle", Belphégor [Online], 18-2 | 2020, Online since 16 December 2020, connection on 28 April 2021. URL: http:// journals.openedition.org/belphegor/3382 ; DOI: https://doi.org/10.4000/belphegor.3382

This text was automatically generated on 28 April 2021.

\section{(c)}

Belphégor est mis à disposition selon les termes de la Licence Creative Commons Attribution - Pas d'Utilisation Commerciale - Pas de Modification 4.0 International. 


\section{Grivel, Charles. Le Corps défait. Études en noir de la littérature fin-de-siècle}

\section{Vittorio Frigerio}

\section{REFERENCES}

Grivel, Charles. Le Corps défait. Études en noir de la littérature fin-de-siècle. Les Âmes d'Atala, 2019. 149 p. ISBN : 978-2-914851-24-4

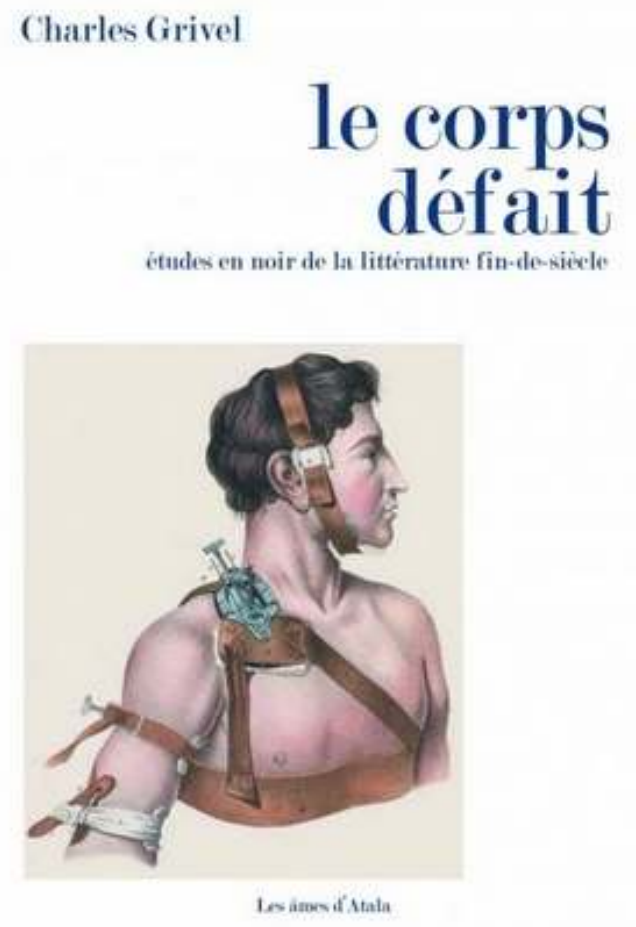


1 Un bon livre de critique littéraire est une machine à voyager dans le temps. Celui-ci l'est à double titre. Dans son acception pourrait-on dire classique - quoique son sujet, ou ses sujets multiples, ne le soient guère - en ce qu'il évoque, reconstruit, commente et suit à la trace une époque littéraire et sa sensibilité particulière : cette fin-de-siècle imbue de symbolisme et de décadentisme, si riche en œuvres suggestives et en auteurs, même "mineurs ", si ce n'est parfois surtout "mineurs", qui valent bien tant des " grands » habituels. Mais il l'est également dans son désir de donner de nouveau la parole à une des personnalités les plus originales et attachantes de la critique dixneuviémiste contemporaine, ce Charles Grivel dont les débuts fracassants se firent en 1973 avec un fort volume, Production de l'intérêt romanesque, du genre qui fait époque, et qui ne se démentit guère le long d'une carrière qui le porta à s'intéresser souvent aux plumes que l'on disait marginales. Dumasien averti alors que le père des trois mousquetaires brillait par son absence de l'histoire littéraire, et que de s'intéresser à son œuvre était accueilli dans les milieux académiques par des haussements dédaigneux de sourcils, Charles Grivel a été parmi les premiers grands chercheurs universitaires à travailler à fond la matière populaire. Et comme le montre ce livre, cela n'a pas été là son unique mérite.

2 La maison d'édition Les Âmes d'Atala, en la personne de son directeur Ian Geay, publie aujourd'hui, à quatre années de distance du décès de l'auteur, ce qui aurait dû être son dernier ouvrage. Et qui l'est, tout en ne l'étant pas. Ce Corps défait, ainsi que l'explique l'éditeur dans son introduction, intitulée très pertinemment « Les livres ne sont pas des livres ", est en réalité autant un « corps refait » que la concrétisation, nécessairement lacunaire, d'une promesse. Promesse de "reficeler ", pour le dire avec le verbe ironique de Grivel lui-même, un certain nombre d'articles précédemment parus dans des revues ou des volumes et, en les liant, rendre encore plus évidente l'unité profonde d'une réflexion originale sur une matière parcourue et analysée à fond lors d'une vie de lectures. La maladie n'a pas voulu que le projet se réalise ainsi que l'auteur l'avait conçu. Geay - dont l'introduction touchante, vrai témoignage d'amitié, restitue le processus de conception et (re)composition de l'ouvrage - nous livre donc un «livre provisoire » (10), doué d'un sommaire idéal (qui permettra à tout lecteur curieux de compléter lui-même le parcours ici donné, en se procurant les articles que l'auteur n'a pas eu le temps de retravailler) et comportant trois chapitres que l'auteur estimait prêts. Le terrain exploré est celui de cette " Fin de siècle [qui] s'acharne [...] à détruire l'image positiviste des corps, harmonie supposée issue de la correspondance fictive établie entre le vu et le voir" (80). Le premier chapitre (qui aurait dû être le cinquième), « Villiers de l'Isle-Adam. Surnaturel et contre-vision », disserte sur le corps féminin, idéal ou artificiel, à travers cet authentique chef-d'œuvre qu'est l'Ève future et par le biais du regard scientiste, puissamment autosatisfait de Tribulat Bonhomet. Le deuxième, "Gourmont et quelques autres luxures ", révèle la place centrale du sexe dans l'imaginaire du temps, et celle non moins essentielle de la photographie, double la plupart du temps non-dit de l'écriture. Le troisième « Goncourt, La Faustin à plusieurs mains. Stratégie polygraphique du secret d'écriture ", suivi en annexe de la nouvelle de Lorrain, "Dolmancé », offre une véritable enquête littéraire où les suspects ont nom «nouveauté ", «transposition » ou "emprunt». Les mains citées appartiennent à Maupassant, Bourget et Lorrain, dans une farandole de récritures et d'allusions. «[N]ous cherchons à pousser à bout le texte » (121), disait Grivel. C'est chose faite. Et au-delà même de toute attente. 
3 Pour clore le volume, faute d'une conclusion, le lecteur aura droit à un beau petit inédit, un court texte de 2013, "Le Bois de justice ", où il reconnaîtra sans peine nombre de thématiques qui apparaissent tout au travers de l'œuvre critique de Grivel, traitées ici littérairement par quelqu'un qui n'a jamais voulu séparer critique et création.

4 On peut regretter quelques coquilles survivantes ici et là, notamment la mystérieuse transformation de tout « qu'il » en « qu fil ». Mais cela ne diminue en rien l'intérêt de la démarche, ni la réussite globale de cette généreuse tentative, qui fait entendre une fois de plus une voix non des moindres de la critique littéraire française de notre époque. Modeste en même temps que riche, l'écriture critique de Charles Grivel voilait souvent son abondance derrière des phrases comme «[j]e ne puis faire mieux là que l'esquisser »... (79) C'est une esquisse aussi que ce livre reconstitué. Mais une esquisse puissante, à traits décidés, qui laisse voir en arrière-fond une structure de pensée solide, des séries d'intuitions systématisées, éprouvées, convaincantes. Un bon livre autant en plein qu'en creux, qui donne, comme il le faut, tout aussi bien à réfléchir qu'à rêver.

\section{AUTHOR}

VITTORIO FRIGERIO

Dalhousie University 